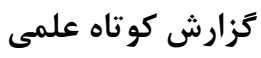

بررسى كاربرد كيتوزان بر جوانهزنى سويا (Glycine max L) در شرايط تنش شورى

وحيد منصورى كندمانى "'،"، حشمت اميدى '، محمد رضايى خر مهينى "

' دانشآموخته كارشناسى ارشد علوم و تكنولوزى بذر، دانشكده علوم كشاورزى، دانشكاه شاهد تهر انهان

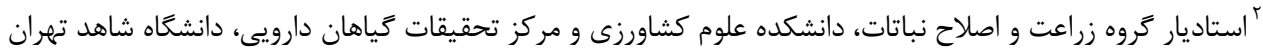

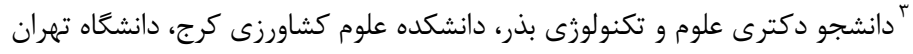

v.mansouri@chmail.ir :

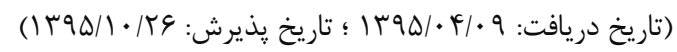

جكيده

بلهنظور بررسى تأثير رِيشتيمار تركيب زيستى كيتوزان بر بذرهاى سويا (Glycine max L) (رقم ويليامز)

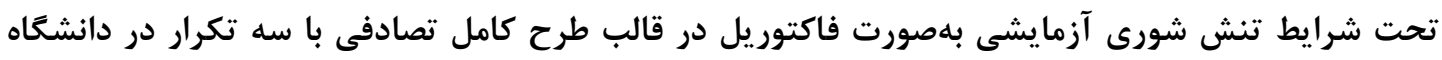

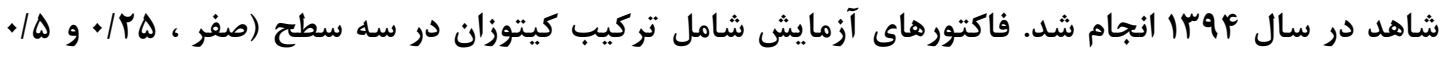

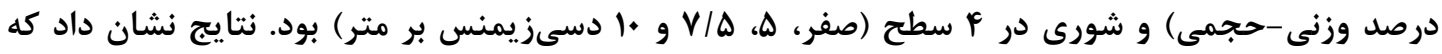

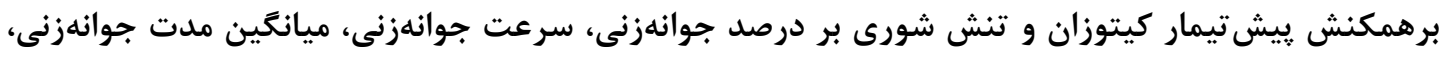

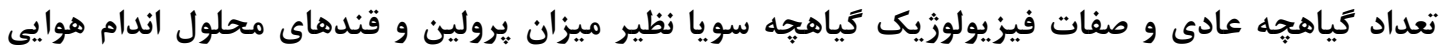

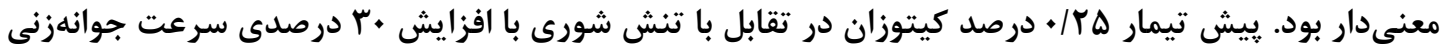

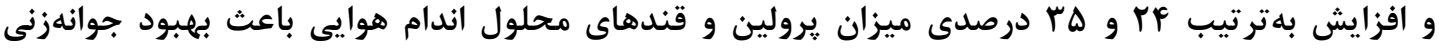

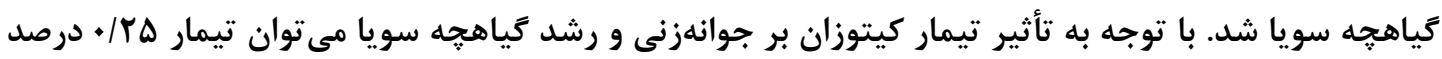

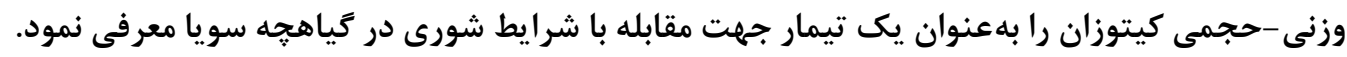

وازههاى كليدى: يرولين، يرايمينَ، تركيب زيستى كيتوزان، قندهاى محلول

علاوه بر تنش شورى با تنش كمآبى مواجه شده كه اين

مقدمه

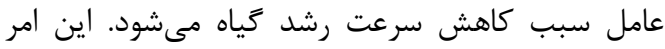

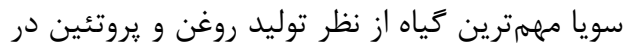

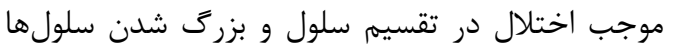

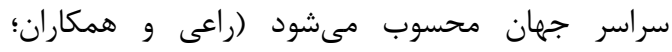
شده و تمام واكنشهاى متابوليكى كياه تحت تأثير قرار هحب IrV

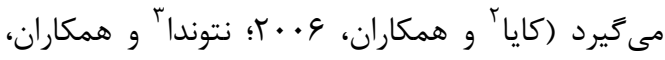

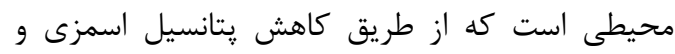

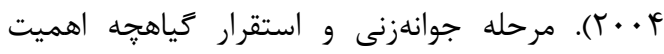
اختلال در جذب برخى عناصر غذايى (يتاسيم و و ويزهاى در تعيين عملكرد دارد و از مهمترين مراحل

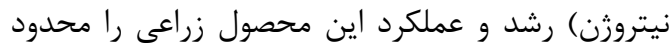
بحرانى در جرخه زندگى كياه مى باشد؛ بنابراين بذرهايى

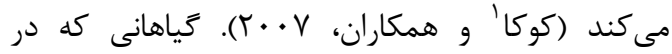

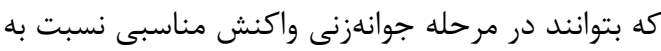
خاكهاى شور رشد مى كنند، به دليل خواص اسمزى،

\footnotetext{
${ }^{2}$ Kaya

${ }^{3}$ Netondo
}

${ }^{1}$ Koca 
ه/ • • و | • درصد وزنى حجمى در نظر گرفته شد

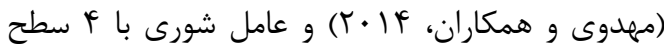
صفر، ه، V/D و • د دسىزيمنس بر متر با استفاده از

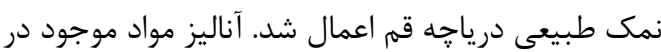
نمك درياجه قم نشان داد كه ميزان غلظت سديم سيم (Na $\left.{ }^{+}\right)$

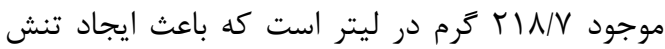
شورى در گياه مىشود. ديخر تركيبات موجود در نمك

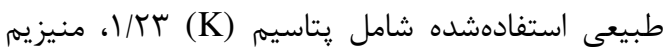
19/D ( $\left.19 \mathrm{Mg}^{+2}\right)$

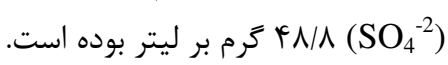

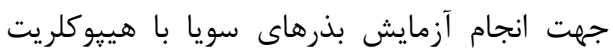

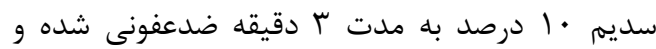
سيس با آب مقطر شستشو داده شدند. بذرهاى در سطوح مختلف تيمار كيتوزان به مدت 9 ساعت قرار

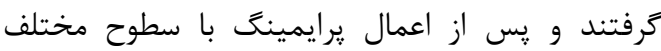

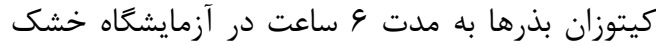
شدند. در هر يترى •r عدد بذر روى كاغذ صافى واتمن

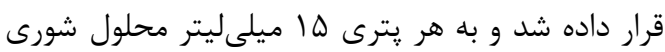

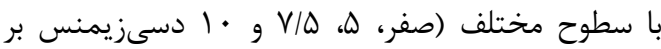
متر) اضافه و براى جلوگيرى از تبخير آب در يترىها به مهنه

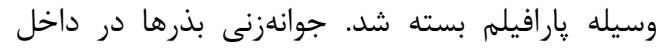

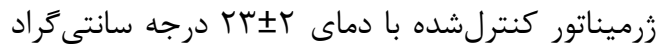
تحت شرايط تاريكى انجام شد. شمارش بذرهاى جوانهزده از روز دوم بلصورت روزانه در ساعتى معين

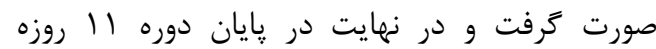
آزمايش، درصد جوانهزده و سرعت جوانهزنى (ياگتر ^و و

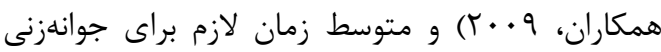

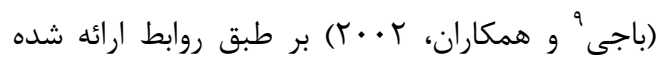
محاسبه گرديد.

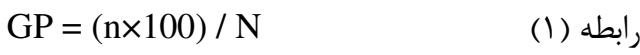
در اين رابطه GP: درصد جوانهزنى، n: مجموع كل بذرهاى جوانهزده در يايان آزمايش، N: كل بذه بذرهاى $\mathrm{GS}=\Sigma \mathrm{ni} / \mathrm{Ti}$ كاشته شده رابطه (r)

\footnotetext{
${ }^{8}$ Pagter

${ }^{9}$ Bajji
}

تنش شورى نشان دهند، در مرحله گياهجهاى رشد بهترى داشته و سيستم ريشهاى قوىترى را توليد

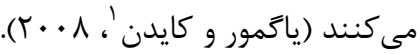
كيتوزان (Beta - 1,4 - D - glucosamine) يكى يلىساكاريد كلوكزامين مشتق شده از كيتين است. در كشاورزى خاصيت ضد باكتريايى و ضد قارجى اين ماده را بهعنوان يك يوشش مناسب براى نكمهدارى و حفظ

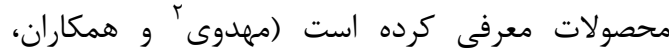

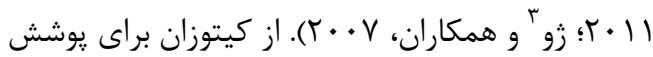

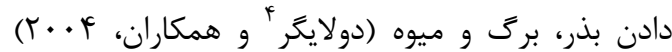
استفاده مىشود. همجنين بهعنوان كود و در كنترل

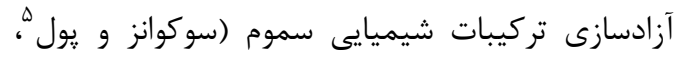

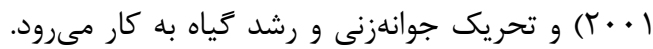

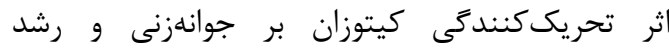

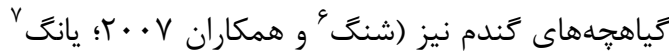

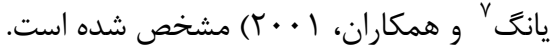
در اين يزوهش با توجه به اينكه جوانهزنى بهعنوان

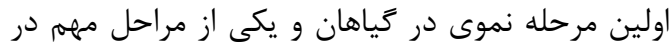

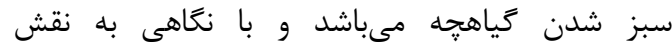
بهبوددهندهى تركيب زيستى كيتوزان در زياه، امكان بهرهگيرى از ريش تيمار كيتوزان بر جوانهزنى بذرهاى

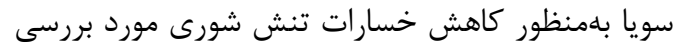

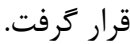

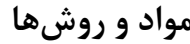

اين آزمايش در سال بوس روا در آزمايشعاه علوم و تكنولوزى بذر دانشكده علوم كشاورزى دانشعاه شاهد

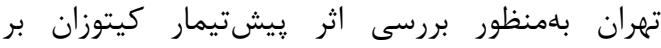

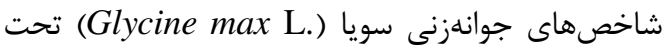
تنش شورى اجرا گرديد. آزمايش بهصورت فاكتوريل در

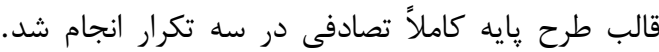

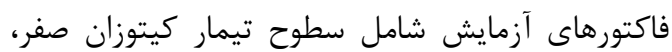

\footnotetext{
${ }^{1}$ Yagmur and Kaydan

${ }^{2}$ Mahdavi

${ }^{3}$ Xue

${ }^{4}$ Devlieghere

${ }^{5}$ Schwanz and Polle

${ }^{6}$ Sheng

${ }^{7}$ Yang
} 
يتانسيل اسمزى باشد، اما حضور يِيشتيمار كيتوزان در سطوح شورى V/D و • • دسىزيمنس بر متر باعث

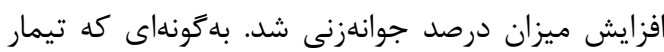

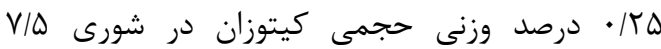
دسىزيمنس بر متر و تيمار ها• درصد كيتوزان باعث

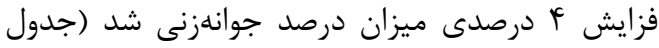

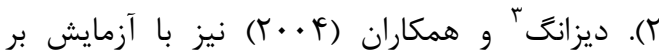
بذرهاى خيسانده ينبه در محلول كيتوزان نشان داد كه كيتوزان باعث افزايش ميزان جوانهزنى در اين كياه شد. همجنين در آزمايشى مشابه اثر افزايشى كيتوزان بران

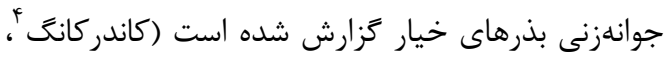

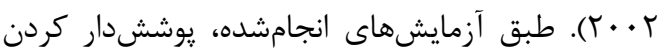

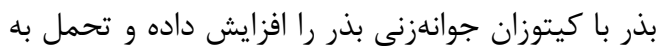

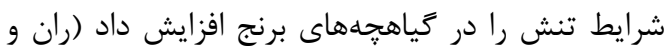

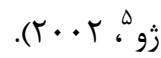

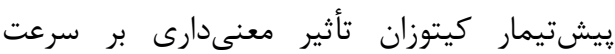

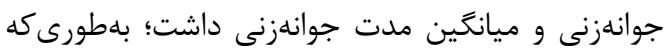
بيشترين سرعت جوانهزنى و كمترين ميانكين زمان

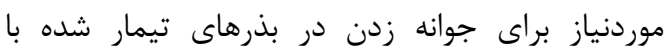

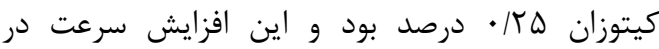

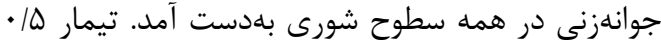

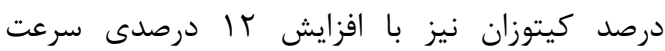

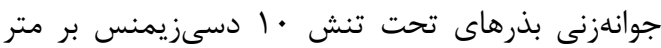

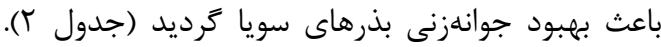
احمد نشان داد بذرهاى آفتابكردان تيمار شده باد باد كيتوزان كه تحت تنش شورى قرار كرفتهاند سرعتى نظير بذرهاى بدون اعمال تنش داشتهاند و كيتوزان با

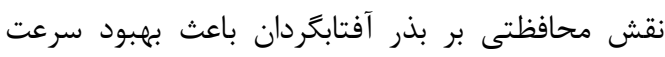

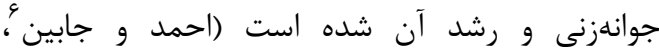

. ( $(r \cdot 1)$

\footnotetext{
${ }^{3}$ Dzung

${ }^{4}$ Chandrkrachang

${ }^{5}$ Ruan and xue
}

${ }^{6}$ Ahmad and Jabeen
در اين رابطه GS: سرعت جوانهزنى، ni: تعداد بذرهاى

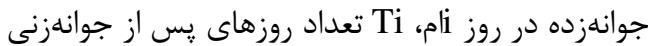
MTG $=\Sigma($ ni) $/ \mathrm{n}$

رابطه (r) در اين رابطه MGT: ميانگين مدت جوانهزنى، ni: تعداد بذرهاى جوانهزده در روز iام، n: مجموع كل بذرهاى جوانهزده در يايان آزمايش بلمنظور اندازهيرى ميزان يرولين و قرئدهاى

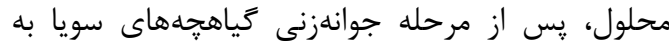

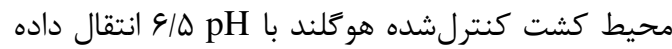
شدند و يس از ايجاد برى حقيقى در زياهجه حدود روز بعد از كشت اندازهگيرى صورت گرفت. ميزان يرولين موجود در اندام گياهجه سويا با استفاده از

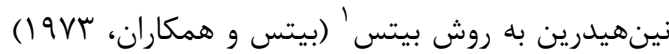

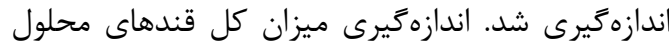

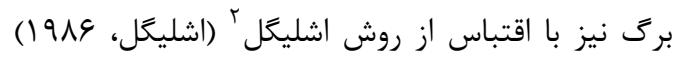

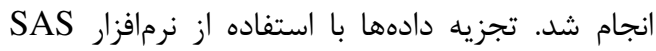
صورت كرفت و مقايسه ميانكينها با استفاده از آزمون جند دامنهاى دانكن در سطح احتمال ه درصد انجام

شد.

نتايج و بحث اثر ييش تيمار كيتوزان، تنش شورى و برهمكنش

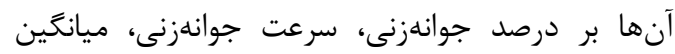
مدت جوانهزنى، تعداد كياهجه عادى، نسبت وزنى رئى ريشه به شاخساره، ميزان يرولين و قندهاى محلول اندام

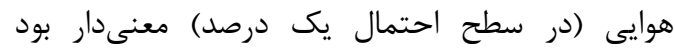
(جدول ()). بر اساس نتايج مقايسه ميانكَين افزايش غلظت شورى باعث كاهش درصد جوانهزنى شد (جدول

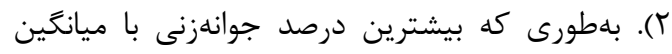

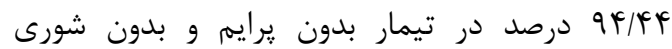

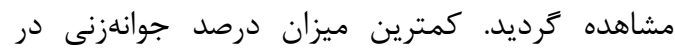
غلظت ·ل دسىزيمنس بر متر شورى و عدم حضد حضور

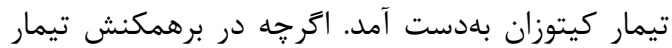
كيتوزان با سطح شورى صفر و ه دسىزيمنس بر متر كاهش جوانهزنى ديده شد كه ممكن است بهدليل إندان

\footnotetext{
${ }^{1}$ Bates

2 Sheligl
} 
منصورى كندمانى و همكاران: بررسى كاربرد كيتوسان بر جوانهزنى سويا در شرايط تنش شورى

جدول ا- تجزيه واريانس يِيشتيمار كيتوزان و تنش شورى براى شاخصهاى جوانهزنى و فيزيولوزيك كياهجه سويا

\begin{tabular}{|c|c|c|c|c|c|c|c|c|}
\hline \multicolumn{7}{|c|}{ ميانخين مربعات } & \multirow[b]{2}{*}{ آزادى درجه } & \multirow[b]{2}{*}{ تغييرات } \\
\hline قميزان & ميزان ״رولين & سشبت وزنه & تعاهداد & ميانگين & جوانهزنى & جوانهزنى درد & & \\
\hline$\cdot / 1 r^{* * * 3}$ & 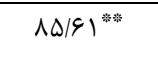 & 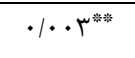 & $9 T / \Delta Y^{* * * 3}$ & $1 / 90^{* * * *}$ & $\Delta \cdot r / V \Delta^{* * *}$ & $1 \mathrm{v} \cdot 199^{* * *}$ & $r$ & كيتوزان \\
\hline$\cdot 1 \cdot \Delta r^{* * * *}$ & $r N / I r^{* * * 3}$ & $\cdot 1 \cdot \cdot 10^{\text {क** }}$ & $\mid \Delta S / T T^{\text {券券 }}$ & $.1 .91^{* * * *}$ & $\Lambda / \wedge \varsigma^{* * * 5}$ & $|V| V / r 9^{* * * 3}$ & r & شورى \\
\hline$\cdot 1 \cdot \Delta^{* * *}$ & $\Delta / 1 Q^{* * * *}$ & $\cdot / \cdot \mid r^{* * * 3}$ & TI/VQ $\Delta^{* * * \%}$ & $\cdot / \cdot V 1^{* * *}$ & $11 / 1 r^{* * * * *}$ & $\mid \wedge 9 / V r^{* * * *}$ & 4 & كيتوزان×شورى \\
\hline$\cdot 1 \cdot \cdot r$ & $\cdot 111$ &. $\mid \cdots 1$ & $1 / 90$ &.$/ \cdot r V$ & .199 & $\mid V / I F$ & TF & خطا \\
\hline$r / q$. & $T / V D$ & $q / 4 T$ & $\mathrm{~V} / \cdot \mathrm{V}$ & $T / \cdot 9$ & $r / \cdot r$ & $41 . r$ & (نرصد) & ضريب تغييرات () \\
\hline
\end{tabular}

جدول r- مقايسه برهمكنش پِيشتيمار كيتوزان و تنش شورى براى صفات جوانهزنى سويا

\begin{tabular}{|c|c|c|c|c|c|c|}
\hline نسبت وزنى ريشه & تعداد زياهجه & جيانگين مدت & جوانهزنى & جوانهزنى درصد & كيتوزان (درصد & شورى (دسىزيمنس \\
\hline.$/ 1 \mathrm{Va}$ & $r \wedge a$ & $r / V b$ & rq/.re & $q f / f \&$ a & صفر & \\
\hline$\cdot / / V \mathrm{c}$ & r r cd & $r / l e$ & $f a / \Delta \wedge b$ & $\Lambda \Delta / \Delta \Delta b$ & $\cdot / \pi \Delta$ & صفر \\
\hline$\cdot / 1 \wedge \mathrm{a}$ & IV f & $r / 9 \mathrm{c}$ & $\mathrm{r} \Lambda \cdot \cdot \wedge \mathrm{d}$ & $\varsigma \Delta / \Delta \Delta c d$ & $\cdot 10$ & \\
\hline.$/ 1 T \mathrm{c}$ & $r \varepsilon \mathrm{ab}$ & $r / A b$ & $r \Delta / r \cdot \mathrm{e}$ & $\wedge \vee / \vee \vee a b$ & صفر & \\
\hline.$/ 1 \mathrm{rc}$ & TFbc & $r / l$ ef & FV/Ira & $11 / 11 \mathrm{~b}$ & $\cdot / \pi \Delta$ & $\Delta$ \\
\hline$\cdot / / \vee a b$ & $\operatorname{lvf}$ & $r / 9 \mathrm{c}$ & $r \Lambda / r d$ & $9 \cdot \mathrm{de}$ & $\cdot 10$ & \\
\hline.$/ 1 \pi \mathrm{c}$ & $r \cdot e$ & $r / r a$ & $r \cdot 10 \cdot f$ & $G \mathrm{~V} / \mathrm{VPc}$ & صفر & \\
\hline.$/ 1 \mathrm{rc}$ & rl de & $r / \cdot V f$ & FN/IFa & $\mathrm{V} / / \mathrm{lc}$ & $\cdot / \pi \Delta$ & $V / \Delta$ \\
\hline$\cdot / / \& b c$ & $\operatorname{lvf}$ & $r / \Delta \mathrm{C}$ & rN/G. d & $9 \cdot \mathrm{de}$ & $\cdot 10$ & \\
\hline.$/ I \vee a b$ & irh & $r / A b$ & $r \Delta / r v e$ & $+9199 \mathrm{~g}$ & صفر & \\
\hline$\cdot / 1 \cdot d$ & $1 \Delta \mathrm{fg}$ & $r / l$ ef & $F V / G \mid a$ & $\Delta F / F F e f$ & $\cdot / \pi \Delta$ & 1. \\
\hline.$/ 1 \mathrm{rc}$ & rgh & $r / F d$ & $F I / F F C$ & $\Delta \cdot f g$ & $\cdot 10$ & \\
\hline
\end{tabular}

ميانكين صفات در هر ستون با حروف متفاوت، نشاندهنده تفاوت معنىدار بر اساس آزمون خجند دامنهاى دانكن در سطح احتمال ه درصد

بر اساس نتايج مقايسه اثر شورى له و دسىزيمنس بر متر بر ميزان رشد ريشه باعث كاهش بر بـ

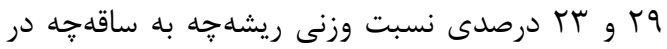
گَياه سويا شده است. تيمار ه| • درصد كيتوزان 9 درصد

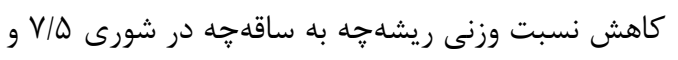

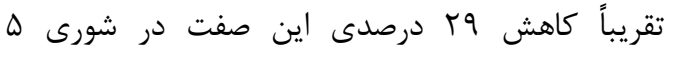
دسىزيمنس بر متر را جبران كرد (جدول r). ريشه

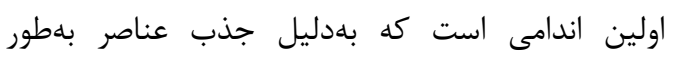
مستقيم با تنش مواجه مىشود (دادرس و همكاران، | (1)). طبق زَزارشها تيمار شورى بر حجم ريشه تأثير
تعداد گياهجه عادى با افزايش شورى كاهش داشت بلهطورى كه بيشترين تعداد كياهجه عادى در عدم حضور شورى با ميانگين ب Y عدد و كمترين تعداد گياهجه عادى در شورى • ا دسىزيمنس بر متر با ميانگين

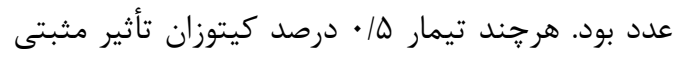

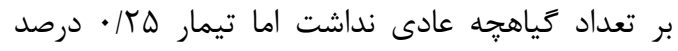

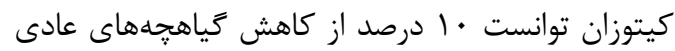
ناشى از تنش شورى • ل1 دسىزيمنس ران جوانبران كند

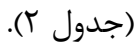


مجله يزوهشهاى بذر ايران/ سال سوم/ شماره دوم/ هوسا

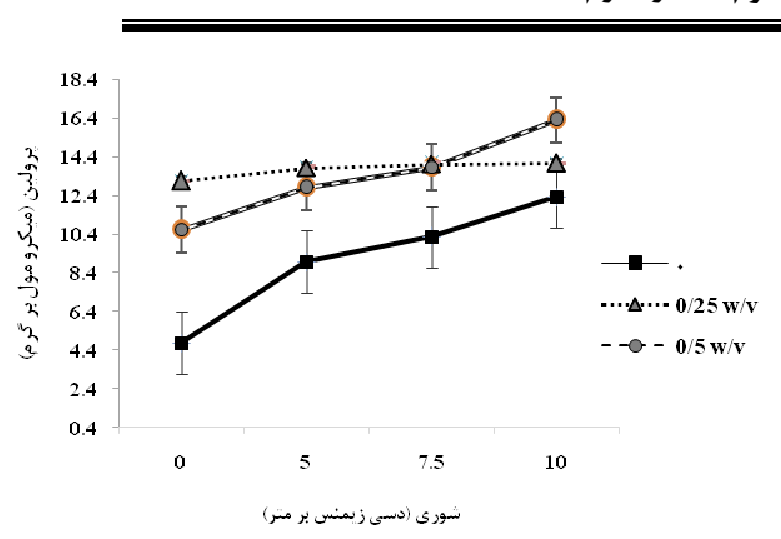

شكل ا- مقايسه برهمكنش شورى و كيتوزان براى ميزان يرولين

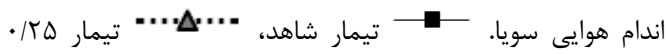

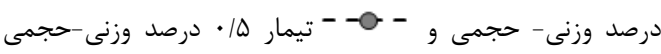

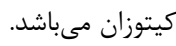

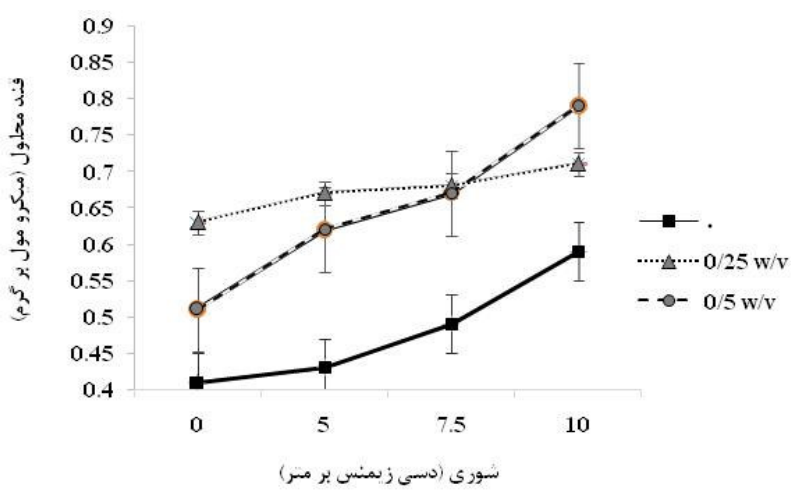

شكل r- مقايسه بر همكنش شورى و كيتوزان براى ميزان قند

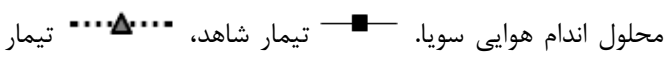

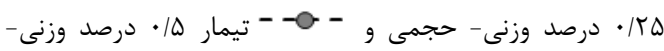

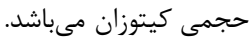

در تنشها راديكال هاى آزاد افزايش مىيابند و باعث بروز تنش اكسيداتيو و آسيب زدن به ساختار غشاء آناء

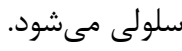

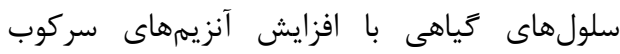
كنندهى راديكالهاى آزاد و افزايش قندها و يروتئينهاى

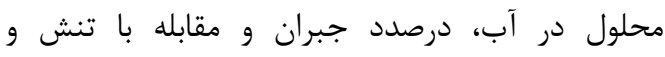

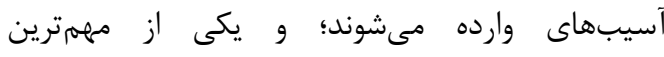

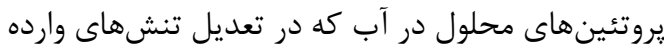
نقش اساسى دارد يرولين است. كيتوزان با افزايش ميزان

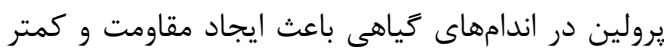

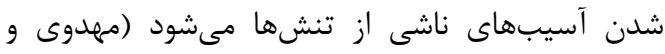

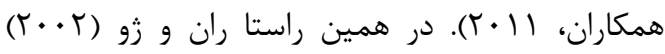

معنى دارى داشت و ميانكين اين صفت با افزايش شورى (رئ كاهش يافت (برزويى و همكاران، حجم ريشه بيشتر و به دنبال آن جذب آن آب و و مواد غذايى

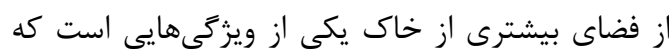

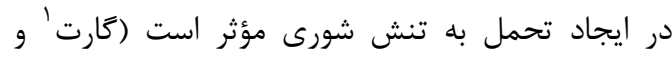

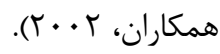

\section{ميزان يرولين و قندهاى محلول اندام هوايى}

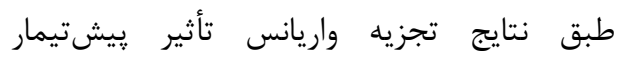

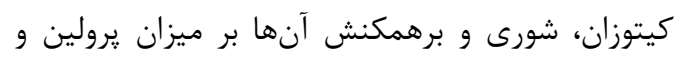

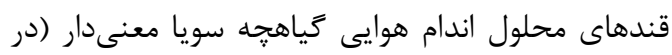
سطح احتمال يك درصد) بود (جدول (). همانطور كه در شكل ا نشان داده شده است گياه براى مقابله با باليا تنش، با افزايش غلظت شورى اندى يرولين بيشترى توليد كرده است. حضور تيمار كيتوزان باعث كمك به افزايش ميزان

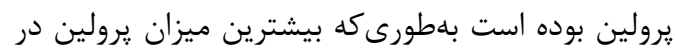

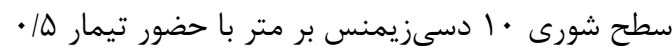

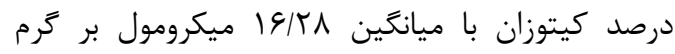

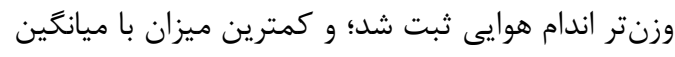
F/VV

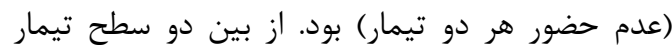

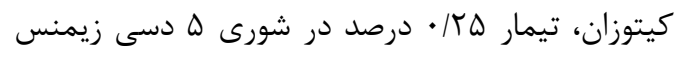

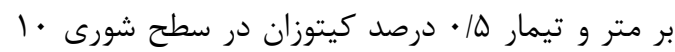
دسىزيمنس بر متر مؤثرتر واقع شد (شكل ()).

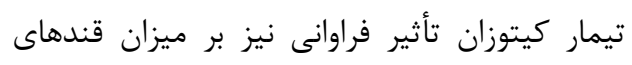
محلول در اندام هوايى كياهجه سويا تحت تنش شورى نيز

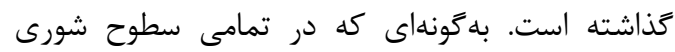
بالاترين ميزان قند محلول با حضور تيمار كيتوزان بود دئه

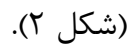

\footnotetext{
${ }^{1}$ Garratt
} 


$$
\begin{aligned}
& \text { محلول اندام هوايى كياهجه سويا رقم ويليامز در شرايط } \\
& \text { نشان دادند كه كيتوزان باعث القاى مقاومت در كياه } \\
& \text { تنش باعث ايجاد مقاومت شد. با توجه به نتايج مقايسه }
\end{aligned}
$$

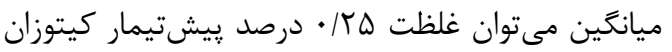

$$
\begin{aligned}
& \text { برنج شده است و با اين مكانيسم عملكرد كياهان زوال } \\
& \text { يافته را بهبود داده است. } \\
& \text { را تيمار مؤثرترى براى كياهجه سويا در شرايط تنش دئ دئن }
\end{aligned}
$$

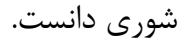

$$
\begin{aligned}
& \text { نتيجه } \\
& \text { بيشتيمار زيستى كيتوزان باعث افزايش سرعت }
\end{aligned}
$$

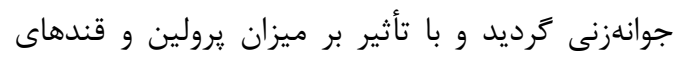

\section{منابع}

Ahmad, R., and Jabeen, N. 2009. Demonstration of growth improvement in sunflower (HellanthusAnnuusL.) by the use of organic fertilizers under saline conditions. Pakistan Journal of Botany, 41(3): 1373-1384.

Bajji, M., Kinet, J.M., and Lutts, S. 2002. Osmotic and ionic effects of $\mathrm{NaCl}$ on germination, early seedling growth, and ion content of Atriplex halimus (Chenopodiaceae). Canadian Journal of Botany, 80(3): 297-304.

Bates, L.S., Waldren, R.P., and Teare I.D. 1973. Rapid determination of free proline for waterstress studies. Plant and Soil, 39(1): 205-207.

Chandrkrachang, S. 2002. The application of chitin and chitosan in agriculture in Thailand. Advances in Chitin Science, 5(1): 458-462.

Devlieghere, F., Vermeulen, A., and Debevere, J. 2004. Chitosan: antimicrobial activity, interactions with food components and applicability as a coating on fruit and vegetables. Food Microbiology, 21(6): 703-714.

Dzung, N. A., and Thang, N.T. 2004. Effect of chitooligosaccharides on the growth and development of peanut (Arachis hypogea L.). In Proceedings of the Sixth Asia-Pacific on Chitin, Chitosan Symposium.(ed.) Khor, E., Hutmacher, D., and Yong, L.L. Singapore, isbn 981-05.

Garratt, L.C., Janagoudr, B.S., Lowe, K.C., Anthony, P., Power, J.B., and Davey, M.R. 2002. Salinity tolerance and antioxidant status in cotton cultures. Free Radical Biology and Medicine, 33(4): 502-511.

Kaya, M.D., Okcu, G., Atak, M., Cıkılı, Y., and Kolsarıcı, O. 2006. Seed treatment to overcome salt and drought stress during germination in sun flower (Helianthus annuus L.). European Journal of Agronomy, 24(4): 291-295. 
Koca, H., Bor, M., Ozdemir, F., and Turkan, I. 2007. The effect of salt stress on lipid peroxidation, antioxidative enzymes and proline content of sesame cultivars. Environmental and Experimental Botany, 60(3): $344-351$.

Mahdavi, B., Modarres Sanavy, S.A.M., Aghaalikhani, M., Sharifi, M., and Dolatabadian, A. 2011. Chitosan improves osmotic potential tolerance in safflower (Carthamus tinctorius L.) seedlings. Journal of Crop Improvement, 25(6): 728-741.

Murungu, F.S., Nyamugafata, P., Chiduza, C., Clark, L.J., and Whalley, W.R. 2003. Effects of seed priming, aggregate size and matric potential on emergence of cotton (Gossypium hirsutum L.) and maize (Zea mays L.). Soil and Tillage Research, 74(2): 161-168.

Netondo, G.W., Onyango, J.C., and Beck, E. 2004. Sorghum and salinity: Response of growth, water relation, and ion accumulation to $\mathrm{NaCl}$ salinity. Crop Science, 44(3): 797-805.

Pagter, M., Bragato, C., Malagoli, M., and Brix, H. 2009. Osmotic and ionic effects of $\mathrm{NaCl}$ and $\mathrm{Na}_{2} \mathrm{SO}_{4}$ salinity on Phragmites australis. Aquatic Botany, 90(1): 43-51.

Ruan, S.L., and Xue, Q.Z. 2002. Effects of chitosan coating on seed germination and salt-tolerance of seedlings in hybrid rice (Oryza sativa L.). Acta Agronomica Sinica, 28(6): 803-808.

Schwanz, P., and Polle, A. 2001. Differential stress responses of antioxidative systems to drought in pedunculate oak (Quercus robur) and maritime pine (Pinus pinaster) grown under high $\mathrm{CO}_{2}$ concentrations. Experimental Botany, 52: 133-143.

Sheligl, H.Q. 1986. The utilization of organic acids by chlorella light. Planta Journal, 47-51.

Sheng, W., Zhang, X.M., Xue, J.P., and Gao, X. 2007. Effect of chitosan on seeds germination and seedling physiological property of wheat. Journal of Biology, 24(2): 51-53.

Xu, Q.J., Nian, Y.G., Jin, X.C., Yan, C.Z., Jin, L. I.U., and Jiang, G.M. 2007. Effects of chitosan on growth of an aquatic plant (Hydrilla verticillata) in polluted waters with different chemical oxygen demands. Journal of Environmental Sciences, 19(2): 217-221.

Yagmur, M., and Kaydan, D. 2008. Alleviation of osmotic stress of water and salt in germination and seedling growth of triticale with seed priming treatments. African Journal of Biotechnology, 7(13): 2156-2162.

Yang, Y., Zhou, Y., Qi, Y., Wang, X., Zhang, Z., and Shi, Y. 2001. Effect of chitosan on physiological activities in germinating seed and seedling leaves of maize. Journal of Hebei Vocationtechnical Teachers College, 15(4): 9-12. 
Short communication

\title{
Application of Chitosan on Soybean (Glycine max L.) Seed Germination under Salt Stress
}

\author{
Vahid Mansoori Gandomani ${ }^{1, *}$, Heshmat Omidi ${ }^{2}$, Mohammad Rezaei Charmahin ${ }^{3}$ \\ ${ }^{I}$ Graduated Master of Science and Seed Technology, Faculty of Agricultural Sciences, Shahed \\ University, Tehran, Tehran, Iran \\ ${ }^{2}$ Assistant Professor of Department Agronomy, College of Agriculture and Medicinal Plant \\ Research Center, Shahed University, Tehran, Tehran, Iran \\ ${ }^{3}$ Ph.D. Student, Seed Science and Technology, College of Agriculture, Karaj, Tehran University, \\ Tehran, Iran \\ *Corresponding author, E-mail address: v.mansouri@ chmail.ir
}

(Received: 29.06.2016 ; Accepted: 15.01.2017)

\begin{abstract}
In order to investigate the effect of pretreatment of chitosan biological compounds on seeds of soybean (Glycine max L. cv. Williams) under salt stress conditions, a factorial experiment was conducted, adopting a completely randomized design with three replications at Shahed University in 2015. Factors examined included the combination of chitosan at three levels $(0,0.25$ and 0.5 the weight-volume) and salinity at 4 levels $(0,5,5.7$ and $10 \mathrm{dS} / \mathrm{m})$. The results showed that the interaction of chitosan and salinity had a significant impact on seed germination characteristics such as germination percentage, germination rate, mean germination time, normal seedling and physiological characteristics such as proline and soluble sugars of shoots. In contrast to salt stress increase of 30\%, and increase of 24 and $35 \%$ of proline and soluble sugars of shoot, pretreatment of chitosan $(0.25 \%)$ improves seedling germination characteristics of soybeans. Given the impact of the treatments of chitosan on seed germination and seedling growth of soybean, it is possible to introduce $0.25 \% \mathrm{~W} / \mathrm{V}$ chitosan as a treatment to deal with conditions of salinity.
\end{abstract}

\section{Keywords: Proline, Priming, Biological compounds chitosan, Soluble sugars}

